\title{
Protective effect of berberine against oxidative stress-induced apoptosis in rat bone marrow-derived mesenchymal stem cells
}

\author{
WANGYANG LI ${ }^{1 *}$, YAMEI LIU ${ }^{2 *}$, BIN WANG $^{1}$, YIWEN LUO $^{1}$, NIANHONG HU ${ }^{1}$, \\ DONGFENG $\mathrm{CHEN}^{3}, \mathrm{XUNCHAO}_{\mathrm{ZHANG}}{ }^{1}$ and YUNPU XIONG ${ }^{1}$
${ }^{1}$ Department of Traumatology, The Third Affiliated Hospital of Guangzhou University of Traditional Chinese Medicine, Guangzhou, Guangdong 510240; Departments of ${ }^{2}$ Diagnostics of Traditional Chinese Medicine and ${ }^{3}$ Anatomy, Guangzhou University of Traditional Chinese Medicine, Guangzhou, Guangdong 510006, P.R. China

Received August 25, 2015; Accepted September 6, 2016

DOI: $10.3892 /$ etm.2016.3866

\begin{abstract}
Bone marrow-derived mesenchymal stem cells (BMSCs) have the potential to be used for the treatment of delayed union, nonunion or persistent bone defects in MSC-based cell therapy. However, implantation of BMSCs into the fracture site is confronted with apoptosis on account of harsh conditions and oxidative stress. In the present study, the anti-apoptotic effects of berberine (BBR) on BMSCs subjected to hydrogen peroxide $\left(\mathrm{H}_{2} \mathrm{O}_{2}\right)$ are investigated, and the potential underlying mechanisms are explored. Oxidative injury was induced by exposure to $\mathrm{H}_{2} \mathrm{O}_{2}$, and cell viability was assessed using a cell counting kit- 8 assay. The apoptosis of BMSCs was measured by Hoechst 33258 and Annexin V-fluorescein isothiocyanate/propidium iodide assay. Reactive oxygen species staining and superoxide dismutase (SOD) assay were applied to assess the anti-oxidative effect of BBR. Finally, western blot was performed to measure the expression levels of phosphorylated (p)-Akt, B-cell lymphoma 2 (Bcl-2), $\mathrm{Bcl}-2$-associated $\mathrm{X}$ protein (Bax) and cleaved caspase-3. In the present study, it was identified that BBR remarkably attenuated $\mathrm{H}_{2} \mathrm{O}_{2}$-induced apoptotic cell death via quenching ROS production and increasing SOD activity. Further studies indicated that $\mathrm{BBR}$ can reduce apoptosis by upregulating the expression level of p-Akt and Bcl-2, and downregulating the expression levels of Bax and cleaved caspase-3. Taken together, the results of the present study demonstrate that pretreatment with BBR could alleviate $\mathrm{H}_{2} \mathrm{O}_{2}$-induced apoptosis in rat BMSCs in vitro.
\end{abstract}

Correspondence to: Professor Bin Wang, Department of Traumatology, The Third Affiliated Hospital of Guangzhou University of Traditional Chinese Medicine, 22 Jiangnan-Xi Road, Guangzhou, Guangdong 510240, P.R. China

E-mail: wangbin1973@163.com

*Contributed equally

Key words: berberine, bone marrow-derived mesenchymal stem cells, bone, apoptosis, oxidative stress

\section{Introduction}

Delayed union and nonunion with or without defects are common complications of traumatic fractures (1). Fortunately, mesenchymal stem cell (MSC)-based therapy has recently emerged as an appealing and potential therapeutic strategy for the treatment of delayed union, nonunion or persistent bone defects (2). Bone marrow-derived MSCs (BMSCs), one type of MSC cell, have the properties of plasticity and the ability to differentiate into chondrocytes, osteocytes and adipocytes (3). The transplantation of BMSCs in damaged tissues has been an innovation used in tissue engineering, particularly in the field of skeletal regenerative medicine $(4,5)$. Cultured BMSCs have been injected or combined with biomaterials into fracture sits where the BMSCs differentiate into osteoblasts to repair the fracture $(2,6,7)$. Therefore, multiple stem cell-based products and techniques to enhance the efficacy of local implantation of BMSCs are currently being investigated to optimize bone healing in various animal models and clinical trials $(3,5)$.

The therapeutic application of BMSCs is limited due to their susceptibility to oxidative stress which results in the engrafted BMSCs' apoptosis in the injured bone area (8-10). Previous studies have demonstrated that BMSCs injected into fracture sites are confronted with its apoptosis within a few days on account of harsh microenvironment conditions with oxidative stress, which is a state of imbalance between reactibe oxygen species (ROS) generation and intracellular antioxidants, resulting in cellular damage, and eventually leading to cell death (11-13). Therefore, strategies to protect the implantation of BMSCs from apoptosis and to improve their survivability in oxidative stress are therapeutically attractive in MSC-based therapy for delayed union, nonunion and persistent bone defects.

Plants used in Traditional Chinese Medicine have been regarded as a wide source of antioxidants with potential pharmacological and biological effects (14). Berberine (BBR), 5,6-dihydro-9,10-dimethoxy-benzo(g)-1,3-benzodioxolo(5 ,6-a) quinolizinium-, chloride, a natural isoquinoline quaternary alkaloid, is a well-known constituent of the Chinese herb Huanglian (15). The compound possesses a variety of pharmacological and biochemical properties, such as anti-inflammatory (16), anti-microbial (17), anti-cancer (18) 
and and antioxidant (19-21) properties. A previous study demonstrated that BBR could attenuate $\mathrm{H}_{2} \mathrm{O}_{2}$-induced oxidative injury in motor neuron-like cells (22), smooth muscle cells (19), endothelial cells and mesangial cells (23), but whether BBR exerts any protective effects against $\mathrm{H}_{2} \mathrm{O}_{2}$ in rat (r)BMSCs is still unknown.

The present study, to the best of our knowledge, demonstrated for the first time that BBR is capable of protecting primary cultural rBMSCs against $\mathrm{H}_{2} \mathrm{O}_{2}$-induced apoptosis via enhancing resistance to oxidative stress in vitro, which could be a promising approach to improve stem cell survival during transplantation in MSC-based therapy for traumatic fractures.

\section{Materials and methods}

Animals and BBR. Male Sprague-Dawley (SD) rats, weight 80-90 g, were obtained from the animal center of Guangzhou University of Traditional Chinese Medicine (Guangzhou, China; certificate no. 44005900001722). Twenty-two rats were specific pathogen-free animals housed with ad libitum access to food and water at a constant temperature of $24 \pm 1^{\circ} \mathrm{C}$ in climate-controlled conditions with a $12 \mathrm{~h}$ light/dark cycle and humidity of $55 \pm 5 \%$. All animals received human care in accordance with the guideline set by the Care of Experiment Animals Committee of Guangzhou University of Chinese Medicine. BBR ( $>99.0 \%$ purity) was provided by the Department of Pharmacology \& Toxicology of Sun Yat-Sen University (Guangzhou, China). BBR was dissolved in dimethyl sulfoxide (DMSO; Sigma-Aldrich; Merck Millipore, Darmstadt, Germany) and kept in $-20^{\circ} \mathrm{C}$ away from the dark. The final concentration of DMSO per well was $0.1 \%$.

Isolation and culture of rBMSCs. MSCs were isolated from the bone marrow of rats as previously reported with minor modification (24). Briefly, the femurs and tibias were clipped from the SD rats under sterile conditions. After removing all the connective tissues and cutting epiphyseal extremities, bone marrow was flushed out with low (L-)glucose Dulbecco's modified Eagle's medium (DMEM) (Gibco; Thermo Fisher Scientific, Inc., Waltham, MA, YSA) containing $1 \%$ penicillin/streptomycin in a sterile petri dish. The cells were centrifuged at $300 \mathrm{xg}$ for $8 \mathrm{~min}$ and resuspended in L-DMEM $(1,000 \mathrm{mg} / 1$ glucose) supplemented with $10 \%$ fetal bovine serum (FBS; Gibco; Thermo Fisher Scientific, Inc.) and a mixture of $1 \%$ penicillin/streptomycin. Bone marrow was transferred to a plastic culture flask and incubated at $37^{\circ} \mathrm{C}$ with $5 \% \mathrm{CO}_{2}$ in a humidified atmosphere. After $24 \mathrm{~h}$, the medium was changed to remove free-floating cells and replaced every 3 days. At $80-90 \%$ confluence, the adherent cells were washed with phosphate-buffered saline (PBS) twice, followed by digestion in $0.25 \%$ trypsin (Gibco; Thermo Fisher Scientific, Inc.) and expanded at a 1:2 dilution.

Cell surface phenotype detection. Surface marker analysis was performed by flow cytometry. rBMSCs were collected in passage three, cells were resuspended in $100 \mu \mathrm{l}$ flow cytometry staining buffer (Cyagen Biosciences, Inc., Guangzhou, China) containing PBS and $0.1 \%$ bovine serum albumin (Sigma-Aldrich; Merck Millipore) at a concentration of
$3 \times 10^{6}$ cells $/ \mathrm{ml}$ and incubated for $30 \mathrm{~min}$ at $4^{\circ} \mathrm{C}$ with the following specific primary antibodies: Anti-rat cluster of differentiation (CD)90, anti-rat CD34 and anti-rat CD11b/c at a concentration of $0.5 \mathrm{mg} / \mathrm{ml}$, which were from the Cyagen Mesenchymal Stem Cell Characterization kit (cat. no. RAXMX-09011; Cyagen Bioscience Inc.) After incubation, the samples were washed twice in $1 \mathrm{ml}$ flow cytometry staining buffer, then centrifuged at $250 \mathrm{x} g$ for $5 \mathrm{~min}$. Then, the supernatant was discarded. Following incubation at $4^{\circ} \mathrm{C}$ with phycoerythrin-conjugated goat anti-rat at a concentration of $1 \mathrm{mg} / \mathrm{ml}$ for $30 \mathrm{~min}$ in the dark, the samples were washed twice with flow cytometry staining buffer, centrifuged at $250 \mathrm{x} g$ for $5 \mathrm{~min}$ and resuspended in $400 \mu \mathrm{l}$ of flow cytometry staining buffer for cytometric analysis. Labeled cells were analyzed by flow cytometry (Coulter EPICS XL; Beckman Coulter, Inc., Brea, CA, USA) with standard software (FACSDiva; version 6.1.3; BD Biosciences, Franklin Lakes, NJ, USA).

Cell viability assay. Cell viability was assessed by detecting the optical density (25). Briefly, rBMSCs were seeded at a density of $1 \times 10^{5} / \mathrm{ml}$ in 96 -well culture plates for $24 \mathrm{~h}$. Subsequently, the cells were pretreated with different concentrations of BBR for $2 \mathrm{~h}$ and then exposed to $\mathrm{H}_{2} \mathrm{O}_{2}$ for $24 \mathrm{~h}$ in $100 \mu \mathrm{l}$ DMEM with $10 \% \mathrm{FBS}$ and $1 \%$ penicillin/streptomycin. Then, $10 \mu \mathrm{l}$ cell counting kit (CCK)-8 solution (Dojindo Laboratories, Kumamoto, Japan) was added into each well. Following $2 \mathrm{~h}$ incubation, the absorbance at a wavelength of $450 \mathrm{~nm}$ was detected using a Bio-kinetics reader (PE-1420; Bio-Kinetics Corporation, Sioux Center, IA, USA). Cell viability was presented as the percentage of the control culture value. The results were calculated using three different batches of wells and each experiment was performed in triplicate as independent experiments.

Morphologic changes. rBMSCs were cultured in 12-well plates for $24 \mathrm{~h}$ and then pretreated with BBR for $2 \mathrm{~h}$ with subsequent exposure to $\mathrm{H}_{2} \mathrm{O}_{2}$ (Sigma-Aldrich; Merck Millipore) for $24 \mathrm{~h}$. Then, cultured cells were washed twice with PBS and fixed with $4 \%$ paraformaldehyde for $10 \mathrm{~min}$ and stained with $2 \mu \mathrm{g} / \mathrm{ml}$ Hoechst 33258 (Sigma-Aldrich; Merck Millipore) for $20 \mathrm{~min}$ at $37^{\circ} \mathrm{C}$ in the dark (26). Then, morphologic changes were observed by phase contrast microscopy and cells images were visualized through a fluorescence microscope.

Apoptosis analysis by flow cytometry. The percentage of apoptotic cells were assessed using Annexin V and propidium iodide (PI) staining (Annexin V-FITC apoptosis detection kit; cat. no. KGA107; Jiancheng Biological Engineering Research Institute, Nanjing, China) and flow cytometry. In brief, rBMSCs were seeded at $5 \times 10^{4}$ cells $/ \mathrm{ml}$ in 6 -well culture plates and incubated overnight. Following treatment, both adherent and floating cells were harvested, washed twice in cold PBS, and resuspended in $200 \mu \mathrm{l}$ of binding buffer (Jiancheng Biological Engineering Research Institute). Annexin V-FITC solution $(5 \mu \mathrm{l})$ was added and the cells were incubated for $30 \mathrm{~min}$ at $4^{\circ} \mathrm{C}$ in the dark. Subsequently, $10 \mu \mathrm{l}$ PI was added and the solution was incubated for $15 \mathrm{~min}$ at the room temperature. The cell suspension was immediately analyzed by flow cytometry (Coulter EPICS XL) with standard software. 
Measurement of ROS production. Production of intracellular ROS was evaluated using a 2'7'-dichlorofluorescein (DCF) assay (27), which was conducted using dichlorofluorescein diacetate $\left(\mathrm{H}_{2} \mathrm{DCF}-\mathrm{DA}\right.$; Sigma-Aldrich; Merck Millipore). Briefly, following treatment, rBMSCs were washed and then

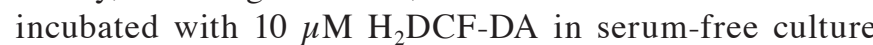
medium (Gibco; Thermo Fisher Scientific, Inc.) for $30 \mathrm{~min}$ at $37^{\circ} \mathrm{C}$ in the dark. DCF fluorescence was illuminated by visual effect of cell morphology through fluorescence microscopy or analyzed using a fluorescence plate reader (Flex Station3; Molecular Devices, LLC, Sunnyvale, CA, USA) at an excitation and emission wavelength of $490 \mathrm{~nm}$ and $533 \mathrm{~nm}$.

Detection of superoxide dismutase (SOD). SOD activity was tested with the xanthine oxidase method as previously described (28). Briefly, rBMSCs were pretreated with BBR for $2 \mathrm{~h}$ and incubated with $600 \mu \mathrm{M} \mathrm{H}_{2} \mathrm{O}_{2}$ for $24 \mathrm{~h}$. Then, the cells were harvested and sonicated with cold $0.9 \%$ sodium chloride to obtain cell homogenates. Following centrifugation at $3,500 \times \mathrm{g}$ at $4^{\circ} \mathrm{C}$ for $5 \mathrm{~min}$, the supernatants were obtained and then used for detecting intracellular SOD. The level of SOD was calculated by measuring the absorbance at $570 \mathrm{~nm}$ according to the instructions of a Superoxide Dismutase Assay kit (cat. no. A001-2; Jiancheng Biological Engineering Research Institute). The basal contents of SOD in untreated control cells were taken as $100 \%$.

Western blotting analysis. Western blotting analysis was performed as previously described (29). Briefly, at the end of the treatment period, cells were collected and lysed with cold lysis buffer. Total protein concentration was determined using a BCA assay kit (cat. no. KGET13; Keygen, Nanjing, China). Protein samples $(30 \mu \mathrm{g} / \mathrm{kg})$ were separated by $10 \%$ SDS-PAGE and transferred onto polyvinylidenedifluoride membranes. After being blocked with 5\% non-fat dry milk in Tris-buffered saline and Tween-20 buffer, the membranes were incubated overnight at $4^{\circ} \mathrm{C}$ with the following the primary antibodies: Rabbit polyclonal anti-phosphorylated (p)-Akt (cat. no. 5012S), anti-B-cell lymphoma 2 (Bcl-2; cat. no. 3498) and anti-caspase-3 (Cat. no. 9661) (all purchased from Cell Signaling Technology, Inc., Danvers, MA, USA; 1:1,000), rabbit polyclone anti-Bcl-2-associated $\mathrm{X}$ protein (cat. no. sc-526; Santa Cruz Biotechnology, Inc., Dallas, TX, USA; 1:500) and mouse polyclonal anti- $\beta$-actin (cat. no. A1978; Sigma-Aldrich; Merck Milliporel 1:10,000) at $4^{\circ} \mathrm{C}$ overnight. The next day, the membranes were incubated for $1 \mathrm{~h}$ at room temperature with horseradish peroxidase-conjugated anti-rabbit secondary antibody (cat. no. sc-3836; Santa Cruz Biotechnology, Inc.; 1:5,000) and anti-mouse secondary antibody (cat. no. W4021; Promega Corporation, Madison, WI, USA; 1:10,000). The bands were detected with enhanced chemiluminescence (GE Healthcare Life Sciences, Chalfont, UK). The blots were quantified using Quantity One software (version 4.62; Bio-Rad Laboratories, Inc., Hercules, CA, USA).

Statistical analysis. All quantified data represent an average of at least three samples, and the results are presented as the mean \pm standard deviation. Differences among groups were tested by one-way analysis of variance (ANOVA). Statistical analyses between two groups were performed by unpaired Student's t-test. Following ANOVA analyses, the Tukey's test was used. $\mathrm{P}<0.05$ was considered to indicate a statistically significant difference. All statistical analyses were performed using GraphPad version 5.0 (GraphPad Software, Inc., La Jolla, CA, USA).

\section{Results}

Morphology and cell surface phenotype detection of $B M S C s$. Fifteen days after being obtained from rat femur, cultured rBMSCs were adherent to the dish and showed an elongated, spindle-shaped and fibroblast-like morphology (Fig. 1A). Furthermore, the phenotype of BMSC-related cell surface markers CD90, CD34 and CD11b were detected. Results of flow cytometry demonstrated that $89.4 \%$ of the cells expressed CD90, $4.8 \%$ of the cells expressed CD11b and $0.2 \%$ of the cells expressed CD34 (Fig. 1B).

Effect of $\mathrm{BBR}$ and $\mathrm{H}_{2} \mathrm{O}_{2}$ on $\mathrm{rBMSC}$ cell viability. CCK-8 assay results demonstrated that BBR (Fig. 2A) did not cause cell death at a concentration of $30 \mu \mathrm{M}$, but significantly reduced cell viability at $30 \mu \mathrm{M}$ compared with the control $(\mathrm{P}<0.01$; Fig. 2B). To determine the optimum concentration of $\mathrm{H}_{2} \mathrm{O}_{2}$ for next experiment, cells treated with 500, 600, $700,800,900$ and $1000 \mu \mathrm{M}$ for $24 \mathrm{~h}$ in the complete medium were examined. $\mathrm{H}_{2} \mathrm{O}_{2}$ exhibited cytotoxicity dose-dependently, and $600 \mu \mathrm{M} \mathrm{H}_{2} \mathrm{O}_{2}$ significantly reduced cell viability by $48.6 \%$ compared with the control $(\mathrm{P}<0.01$; Fig. $2 \mathrm{C})$. This concentration was used for the following experiments.

BBR inhibited $\mathrm{H}_{2} \mathrm{O}_{2}$-induced cell inhibition in $r B M S C s$. To examine whether BBR protects rBMSCs from $\mathrm{H}_{2} \mathrm{O}_{2}$-induced cell death, cells were pretreated with 1,3 and $10 \mu \mathrm{M}$ BBR for $2 \mathrm{~h}$, then incubated with $\mathrm{H}_{2} \mathrm{O}_{2}(600 \mu \mathrm{M})$ for $24 \mathrm{~h}$. The results demonstrated that the cell viability of BMSCs in the $\mathrm{H}_{2} \mathrm{O}_{2}$ group decreased dramatically, while BBR dose-dependently increases the cell viability. $\mathrm{BBR}$ at $3 \mu \mathrm{M}$ showed the best effect against $\mathrm{H}_{2} \mathrm{O}_{2}\left(\mathrm{P}<0.01\right.$ vs. the $\mathrm{H}_{2} \mathrm{O}_{2}$ group; Fig. 2D).

BBR reduced $\mathrm{H}_{2} \mathrm{O}_{2}$-induced apoptosis-like cell death in rBMSCs. Hoechst 33258 staining was applied and observed by fluorescence microscope to detect changes in cell nuclei. After pretreatment with BBR, the number of cells with bright blue fluorescence were reduced notably, indicating that BBR can markedly decrease the number of apoptotic cells and nuclear condensation (Fig. 3A) caused by $\mathrm{H}_{2} \mathrm{O}_{2}$. The results of Annexin V-FITC/PI staining detected by flow cytometery revealed (Fig. 3B and C) that the $\mathrm{H}_{2} \mathrm{O}_{2}$ treatment group had a significantly higher rate of apoptosis $(36 \pm 3.39 \%)$ compared with the control group $(0.14 \pm 0.02 \%)(\mathrm{P}<0.01)$. However, the addition of BBR was able to protect the cells against $\mathrm{H}_{2} \mathrm{O}_{2}$-induced apoptosis and significantly reduce the rate of apoptotic cells $(\mathrm{P}<0.01 ; 22 \pm 4.21 \%)$.

BBR suppressed $\mathrm{H}_{2} \mathrm{O}_{2}$-induced intracellular $\mathrm{ROS}$ formation. To elucidate the potential mechanisms underlying the protection of BBR following $\mathrm{H}_{2} \mathrm{O}_{2}$ treatment, H2DCF-DA staining, a ROS probe, was used to measure cellular oxidative stress by DCF fluorescence. Treatment with $600 \mu \mathrm{M}$ 
A

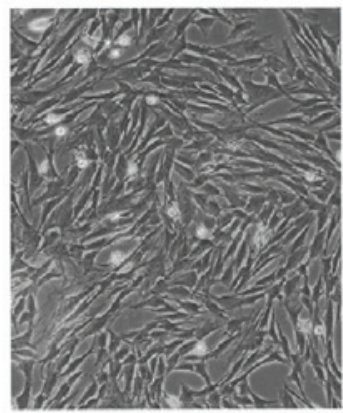

B

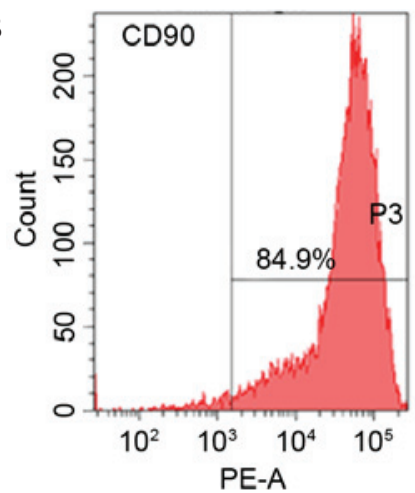

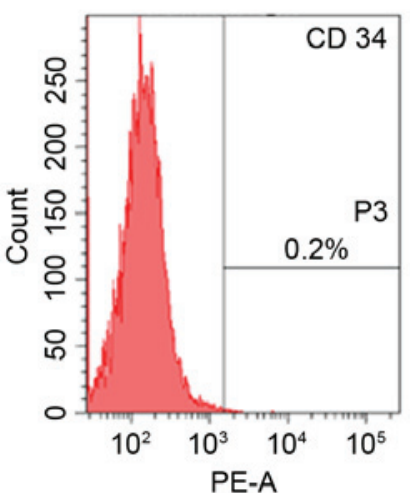

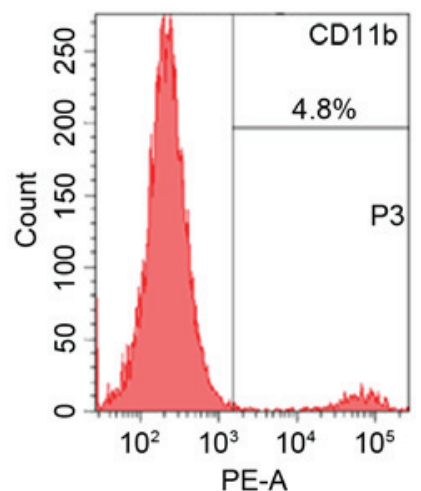

Figure 1. Characterization of cell morphology and surface phenotype of rBMSCs at passage 3. (A) Representative phase-contrast microscopy image of rBMSCs with typical spindle-shaped and fibroblast-like morphology. Magnification, x100. (B) Flow cytometry analysis showing that rBMSCs express CD90, CD34 and CD11b. CD, cluster of differentiation; PE-A, phycoerythrin absorbance; rBMSC, rat bone marrow-derived mesenchymal stem cell.

A<smiles></smiles>

C

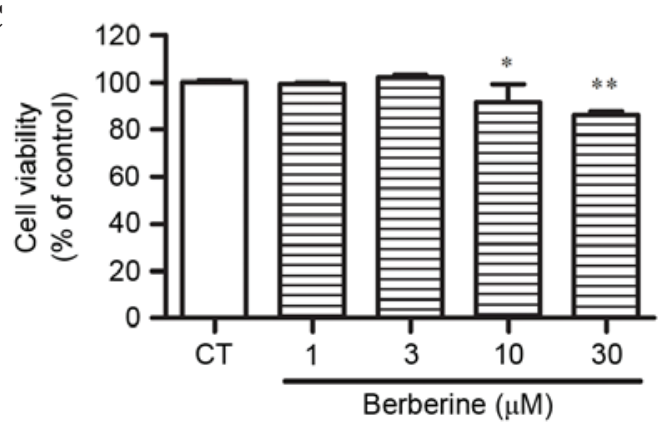

B

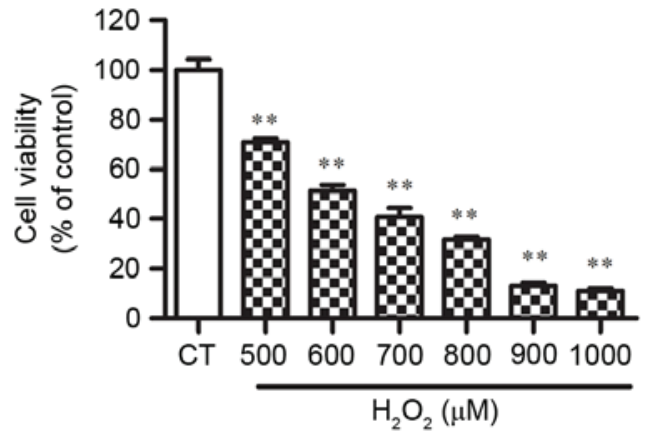

D

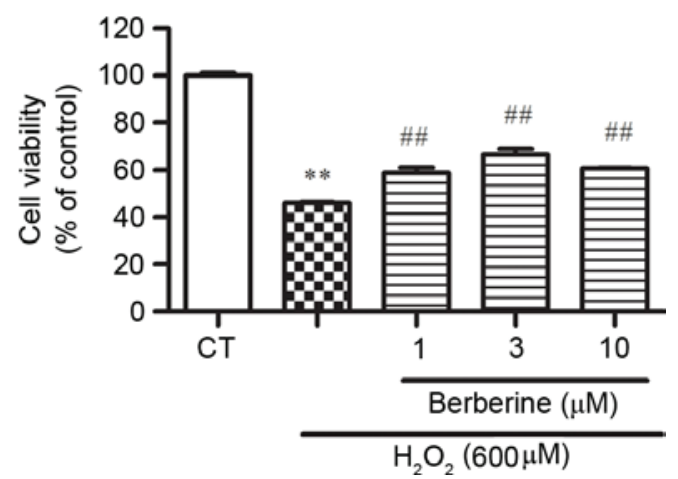

Figure 2. Effect of BBR and $\mathrm{H}_{2} \mathrm{O}_{2}$ on cell viability detected by CCK-8 assay. (A) Structure of BBR. (B) Cells were treated with different concentrations of BBR for $24 \mathrm{~h}$. (C) The viability of cells treated with 500-1000 $\mu \mathrm{M} \mathrm{H}_{2} \mathrm{O}_{2}$ decreased dose-dependently. (D) rBMSCs were pretreated with 1,3 and $10 \mu \mathrm{M}$ BBR for $2 \mathrm{~h}$, then incubated with $\mathrm{H}_{2} \mathrm{O}_{2}(600 \mu \mathrm{M})$ for $24 \mathrm{~h}$. ${ }^{*} \mathrm{P}<0.05,{ }^{* * *} \mathrm{P}<0.01$ vs. the control group; ${ }^{\# \#} \mathrm{P}<0.01$ vs. the $\mathrm{H}_{2} \mathrm{O}_{2}$-treated group. Data are presented as mean plus standard deviation. The bar graphs represent three independent experiments. BBR, berberine; CCK-8, cell counting kit-8; CT, control; rBMSCs, rat bone marrow-derived mesenchymal cells.

$\mathrm{H}_{2} \mathrm{O}_{2}$ for $24 \mathrm{~h}$ significantly resulted in the increase of DCF fluorescence compared with the control group $(\mathrm{P}<0.01)$, which was significantly reversed by $\mathrm{BBR}(\mathrm{P}<0.01$; Fig. 4A and $\mathrm{B})$. 
A

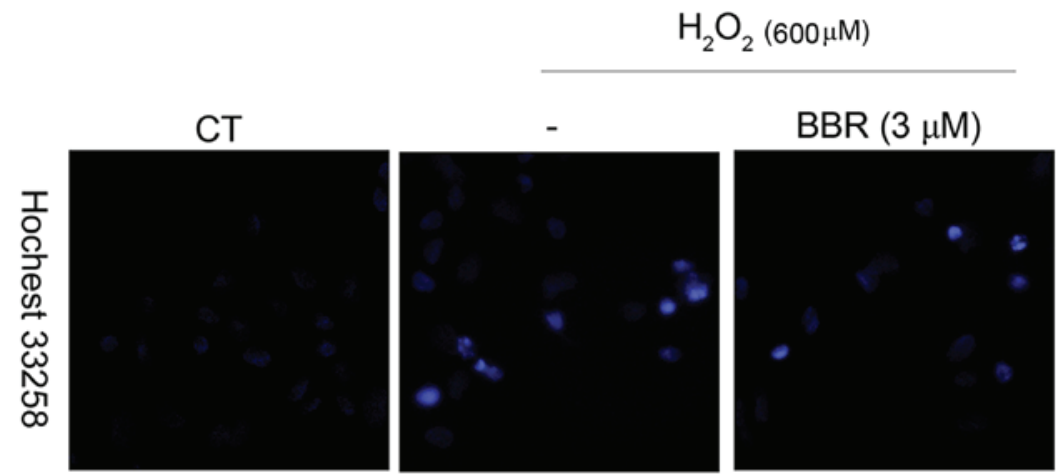

B

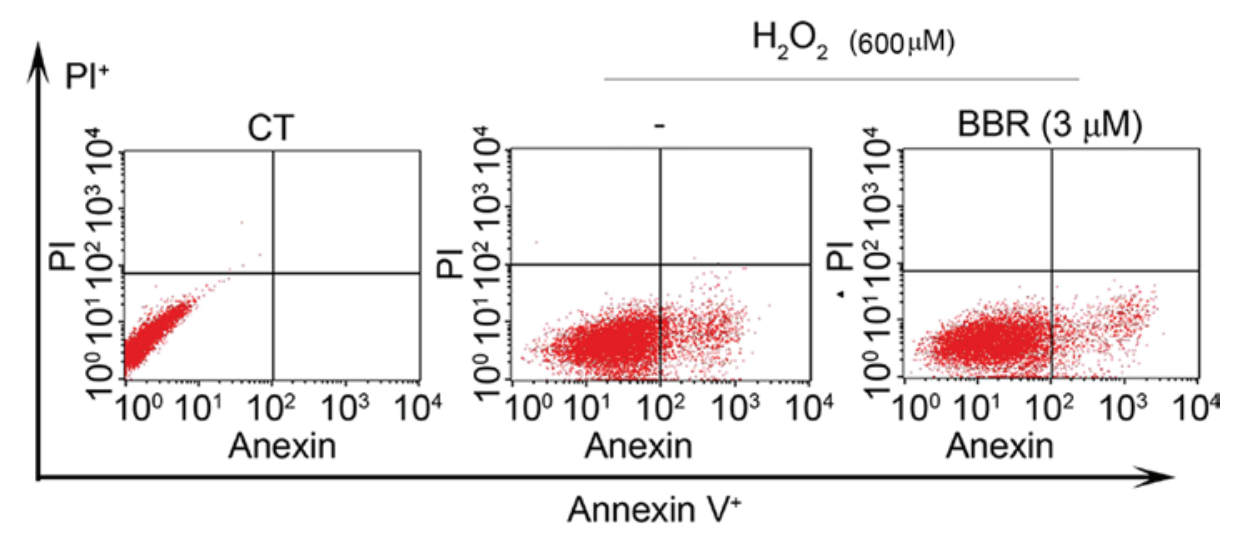

C

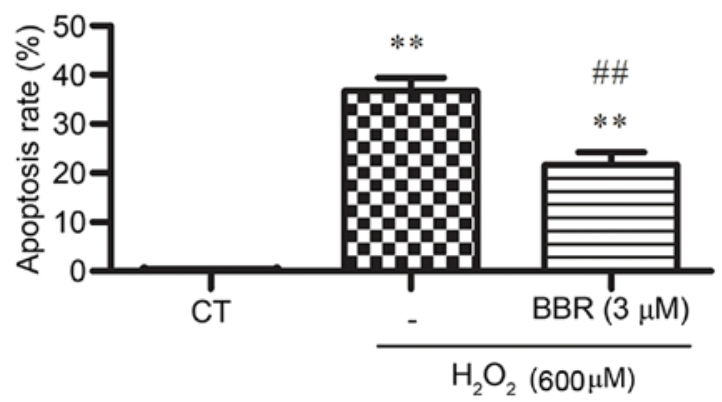

Figure 3. BBR significantly lowered $\mathrm{H}_{2} \mathrm{O}_{2}$-induced apoptosis in rBMSCs. Cells were pretreated with or without $3 \mu \mathrm{M}$ BBR for 2 h prior to exposure to $\mathrm{H}_{2} \mathrm{O}_{2}$ $(600 \mu \mathrm{M})$. (A) Nuclear condensation was assessed using Hoechst 33258. Magnification, x200. (B) Apoptosis was assessed using Annexin V-FITC/PI staining. (C) Quantitative analysis of apoptotic cells. ${ }^{* *} \mathrm{P}<0.01$ vs. the control group; ${ }^{\# \#} \mathrm{P}<0.01$ vs. the $\mathrm{H}_{2} \mathrm{O}_{2}$ group. Results are shown as the mean plus standard deviation. BBR, berberine; CT, control; FITC, fluorescein; PI, propidium iodide; rBMSCs, rat bone marrow-derived mesenchymal stem cells.

BBR alleviated $\mathrm{H}_{2} \mathrm{O}_{2}$-induced decrease of the activity of intracellular SOD. To further study whether BBR could alleviate $\mathrm{H}_{2} \mathrm{O}_{2}$-induced oxidative stress, the activity of SOD in rBMSCs was assessed. As shown in Fig. 4C, the activity of SOD was significantly decreased in the $\mathrm{H}_{2} \mathrm{O}_{2}$-treated group compared with that of the control group $(\mathrm{P}<0.01)$, while pretreatment of BBR significantly restored this decrease in SOD activity $(\mathrm{P}<0.05)$.

BBR protectedrBMSCs from $\mathrm{H}_{2} \mathrm{O}_{2}$-induced apoptosis viaregulation of the expression of apoptosis-related proteins $p$-Akt, $B c l-2$, Bax and caspase-3. To further explore the protective mechanisms of BBR, the expression of anti-apoptotic protein $\mathrm{Bcl}-2$, and the pro-apoptotic proteins Bax and caspase-3, were investigated. As shown in Fig. 5A-D, following treatment with
$\mathrm{H}_{2} \mathrm{O}_{2}(600 \mu \mathrm{M})$ for $12 \mathrm{~h}$, it was observed that the expression of $\mathrm{Bcl}-2$ significantly decreased $(\mathrm{P}<0.05)$, and the expression of Bax and caspase-3 significantly increased $(\mathrm{P}<0.01)$, compared with the control group. Pretreatment with BBR $(3 \mu \mathrm{M})$ for $2 \mathrm{~h}$ significantly inhibited the downregulation of anti-apoptotic proteins $(\mathrm{P}<0.01)$ and significantly reduced the upregulation of pro-apoptotic proteins $(\mathrm{P}<0.01)$. The phosphorylation of Akt had been reported to be important in cell survival and apoptosis (30). In the current study (Fig. 5E), treatment with $\mathrm{H}_{2} \mathrm{O}_{2}(600 \mu \mathrm{M})$ significantly decreased the expression level of pSer473-Akt compared with the control group $(\mathrm{P}<0.01)$, and this was significantly reversed with pretreatment with BBR (3 $\mu \mathrm{M} ; \mathrm{P}<0.01$ ). These results suggest that $\mathrm{BBR}$ can protect rBMSCs from $\mathrm{H}_{2} \mathrm{O}_{2}$-induced apoptosis by increasing the level of p-Akt. 
A
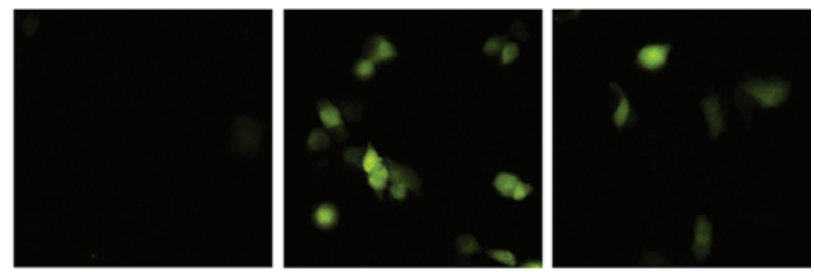

B

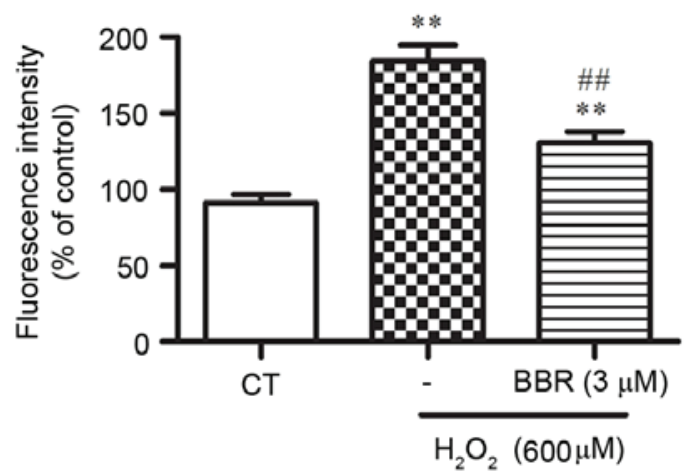

C

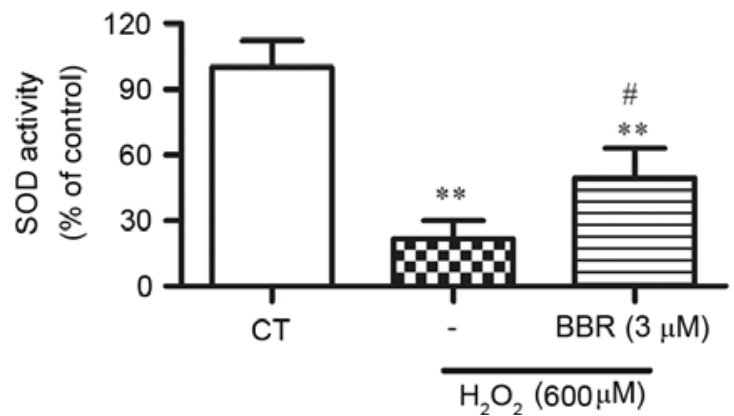

Figure 4. BBR scavenges intracellular ROS produced by $\mathrm{H}_{2} \mathrm{O}_{2}$ in $\mathrm{rBMSCs}$. (A) ROS production induced by $\mathrm{H}_{2} \mathrm{O}_{2}$ detected by $\mathrm{H}_{2}$ DCFH-DA assay. The higher the ROS level, the lighter the fluorescence in the typical photos acquired by a fluorescence microscope. Magnification, x200. (B) Quantitative analysis of DCF fluorescent intensity. (C) The activity of intracellular SOD. ${ }^{* *} \mathrm{P}<0.01$ vs. the control group; ${ }^{\#} \mathrm{P}<0.05,{ }^{\# \#} \mathrm{P}<0.01$ vs. the $\mathrm{H}_{2} \mathrm{O}_{2}$ group. Results are shown as the mean plus standard deviation. $n=3$ in each group. BBR,berberine; DCF, 2'7'-dichlorofluorescein; rBMSCs, rat bone marrow-derived mesenchymal stem cells; SOD, superoxide dismutase.

\section{Discussion}

Treatment of delayed healing, nonunion or a persistent bone defect represents a major challenge for traumatology department (31). Owing to the low immunogenicity and transplantability (32), BMSCs are an effective resource for transplantation in clinical application, with the establishment of cell banks for bone regenerative medicine (2,33). Previously, much attention has been directed towards the poor survival of transplantation in MSC-based therapy $(5,9,34,35)$. For basic and clinician scientists, it is necessary to utilize strategies to improve low cell survival rates.

$\mathrm{H}_{2} \mathrm{O}_{2}$ has been extensively used to imitate the microenvironment surrounding transplanted cells in injured tissue in vitro (36). When exposed to $\mathrm{H}_{2} \mathrm{O}_{2}$, cells are faced with high concentration of ROS, which consequently damages the balance of oxidants and antioxidants, resulting in apoptosis and eventually necrosis. In the experiments in the current study, BBR significantly reduced the level of apoptosis in
$\mathrm{H}_{2} \mathrm{O}_{2}$-treated cells. In addition, the results demonstrated that BBR exposure inhibited the overproduction of intracellular ROS induced by exogenous $\mathrm{H}_{2} \mathrm{O}_{2}$, and significantly enhanced the activity of antioxidant enzyme SOD, which promotes a balance between the ROS and anti-oxidative system in targeting oxidative stress.

Caspase- 3 is the most crucial downstream apoptosis protease in the caspase cascade, which executes apoptosis through DNA degradation, chromatin condensation and nuclear fragmentation (37). In the present study, treatment of rBMSCs with $600 \mu \mathrm{M} \mathrm{H}_{2} \mathrm{O}_{2}$ induced marked nuclear condensation and apoptotic death, and increased the expression of cleaved caspase-3, indicating that the apoptosis of the caspase cascade may be activated by $\mathrm{H}_{2} \mathrm{O}_{2}$. However, following pretreatment with BBR $(3 \mu \mathrm{M})$, the expression of cleaved caspase-3 was significantly reduced, indicating the BBR effectively attenuates oxidative injury by suppressing $\mathrm{H}_{2} \mathrm{O}_{2}$-induced caspase activation.

To further explore the molecular mechanisms underlying the moderation of apoptosis by BBR, the expression level of vital apoptotic proteins was assessed. The Bcl-2 family of proteins comprise the anti-apoptotic proteins and pro-apoptotic proteins, of which the relative proportions control the fine balance between cell survival and cell death via the intrinsic apoptotic pathway (38). In the present study, western blot indicated that BBR could reverse the reduction of the anti-apoptotic protein $\mathrm{Bcl}-2$, and could increase the level of pro-apoptotic protein Bax, following treatment with $\mathrm{H}_{2} \mathrm{O}_{2}$. In addition, pretreatment with BBR prior to incubation with $\mathrm{H}_{2} \mathrm{O}_{2}$ significantly increased the ratio of $\mathrm{Bcl}-2 / \mathrm{Bax}$ compared with cells treated with $\mathrm{H}_{2} \mathrm{O}_{2}$ alone, showing that the Bcl-2 family has a close association with the protective effects of BBR in rBMSCs.

As a survival pathway, the Akt signaling pathway mediating the anti-apoptosis mechanism is well understood (30). Exogenous $\mathrm{H}_{2} \mathrm{O}_{2}$ can influence Akt activation, which promotes cell survival (39). The present study showed that BBR pretreatment prevented the downregulation of p-Akt induced by $\mathrm{H}_{2} \mathrm{O}_{2}$. This suggests that BBR caused an increase of Akt phosphorylation in parallel with an increase of protective effects. However, whether BBR can protect rBMSCs from oxidative stress-induced apoptosis via the Akt pathway requires further investigation.

In conclusion, the results of the present study provide powerful evidence that pretreatment with BBR can alleviate $\mathrm{H}_{2} \mathrm{O}_{2}$-induced apoptosis and enhance the viability of rBMSCs via improvement of antioxidant activities and regulation of apoptosis and the anti-apoptotic pathway. This may be a useful strategy to improve low cell survival rates in treatment of delayed union and nonunion with or without defects.

\section{Acknowledgements}

The authors would like to thank Miss Meihui Chen who worked in Guangdong Provincial Hospital of Traditional Chinese Medicine (Guangzhou, China) for assisting in the preparation of this manuscript. The present study was supported by National Natural Scientific Foundation of China (grant no. 81273783) and the National Natural Scientific Foundation of China (grant no. 81473699). 
A

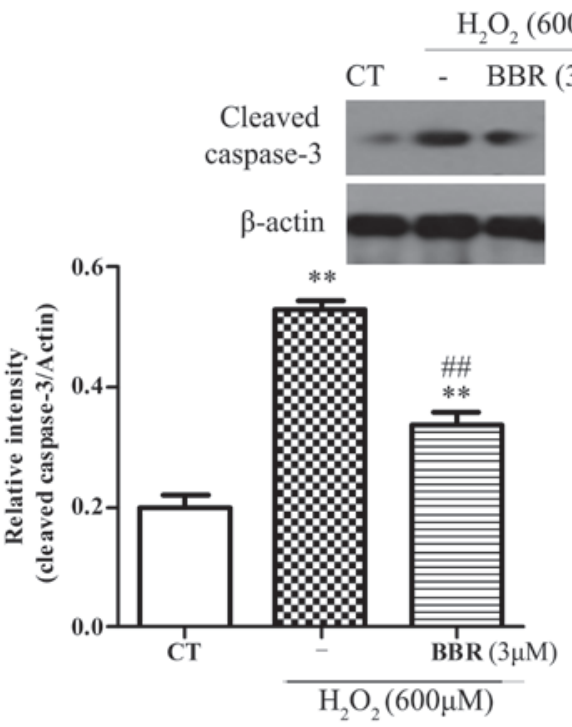

C

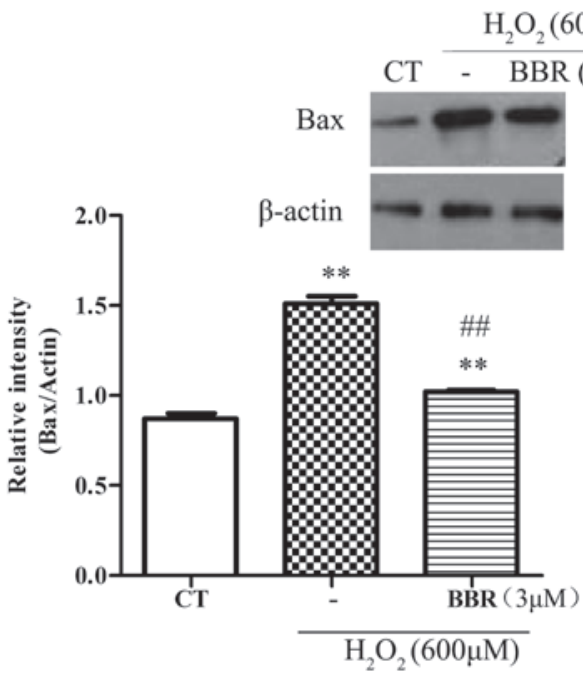

$\mathbf{E}$

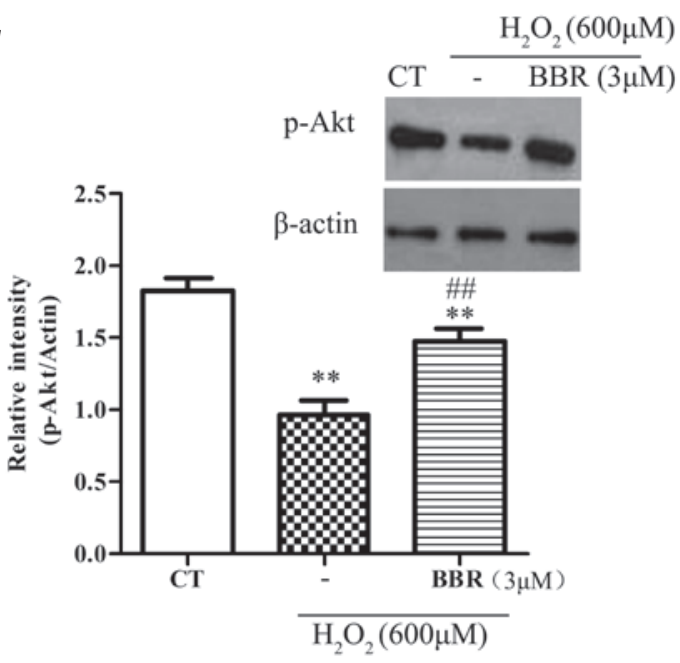

B
$\mathrm{H}_{2} \mathrm{O}_{2}(600 \mu \mathrm{M})$

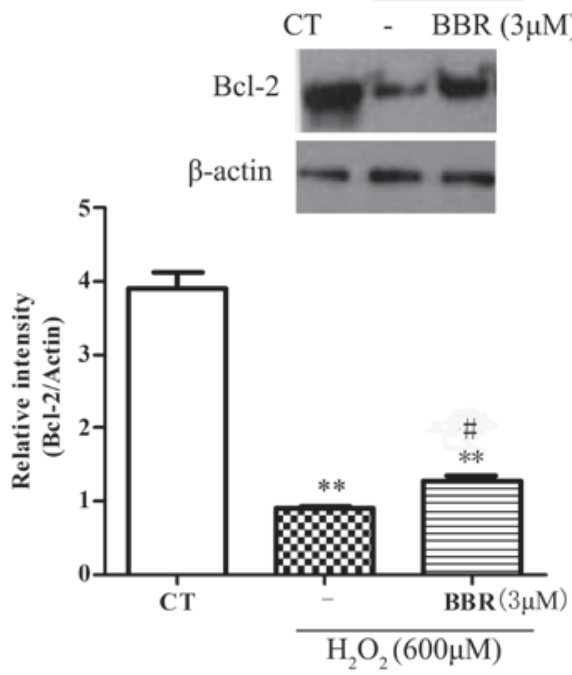

$\mathbf{D}$
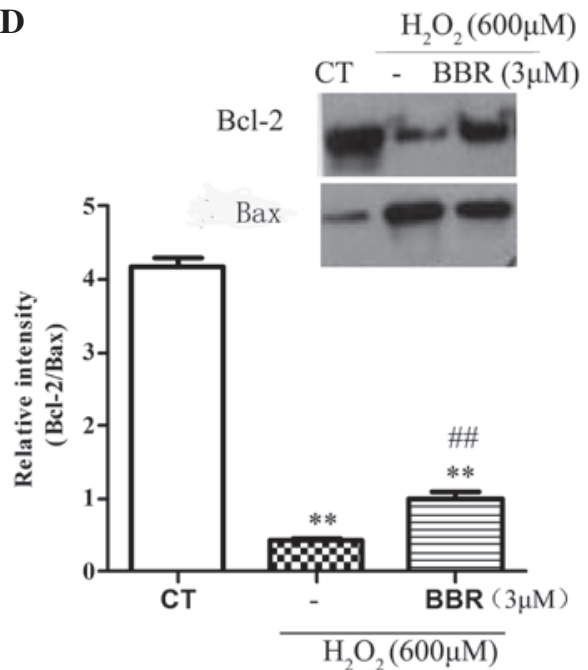

Figure 5. Representative western blots showing the effects of BBR on Bcl-2, Bax, caspase- 3 and p-Akt expression in rBMSCs. $\beta$-actin was used as a loading control. Cells were pretreated with BBR for $2 \mathrm{~h}$ followed by treatment with $\mathrm{H}_{2} \mathrm{O}_{2}(600 \mu \mathrm{M})$ for $12 \mathrm{~h}$. (A) Following pretreatment with BBR, the expression of caspase-3 significantly reduced compared with the $\mathrm{H}_{2} \mathrm{O}_{2}$ group. (B) BBR inhibited the $\mathrm{H}_{2} \mathrm{O}_{2}$-induced downregulation of $\mathrm{Bcl}-2$. (C) $\mathrm{BBR}$ suppressed the $\mathrm{H}_{2} \mathrm{O}_{2}$-induced upregulation of Bax. (D) Increased ratio of Bcl-2/Bax was observed when the cells were pretreated with $\mathrm{BBR}$ prior to incubation with $\mathrm{H}_{2} \mathrm{O}_{2}$. (E) Treatment with $\mathrm{H}_{2} \mathrm{O}_{2}$ significantly decreased the level of p-Akt, which was blocked following pretreatment with $\mathrm{BBR}(3 \mu \mathrm{M}){ }^{* * *} \mathrm{P}<0.01 \mathrm{vs}$. the control group; ${ }^{~} \mathrm{P}<0.05,{ }^{\# \#} \mathrm{P}<0.01$ vs. the $\mathrm{H}_{2} \mathrm{O}_{2}$ group. All data are presented as the mean plus standard deviation of three independent experiments. BBR, berberine; Bcl-2, B-cell lymphoma 2; Bax, Bcl-2-associated X protein; CT, control; p-Akt, phosphorylated Akt; rBMSCs, rat bone marrow-derived mesenchymal stem cells. 


\section{References}

1. Nauth A, Miclau T III, Li R and Schemitsch EH: Gene therapy for fracture healing. J Orthop Trauma 24 (Suppl 1): S17-S24, 2010.

2. Rosset P, Deschaseaux F and Layrolle P: Cell therapy for bone repair. Orthop Traumatol Surg Res 100 (Suppl 1): S107-S112, 2014.

3. Asatrian G, Pham D, Hardy WR, James AW and Peault B: Stem cell technology for bone regeneration: Current status and potential applications. Stem Cells Cloning 8: 39-48, 2015.

4. Qin Y, Guan J and Zhang C: Mesenchymal stem cells: Mechanisms and role in bone regeneration. Postgrad Med J 90: 643-647, 2014

5. Gómez-Barrena E, Rosset P, Lozano D, Stanovici J, Ermthaller C and Gerbhard F: Bone fracture healing: Cell therapy in delayed unions and nonunions. Bone 70: 93-101, 2015.

6. Devine MJ, Mierisch CM, Jang E, Anderson PC and Balian G: Transplanted bone marrow cells localize to fracture callus in a mouse model. J Orthop Res 20: 1232-1239, 2002.

7. Taguchi K, Ogawa R, Migita M, Hanawa H, Ito $\mathrm{H}$ and Orimo $\mathrm{H}$ : The role of bone marrow-derived cells in bone fracture repair in a green fluorescent protein chimeric mouse model. Biochem Biophys Res Commun 331: 31-36, 2005.

8. Majzunova M, Dovinova I, Barancik M and Chan JY: Redox signaling in pathophysiology of hypertension. J Biomed Sci 20 : 69, 2013.

9. Lee S, Choi E, Cha MJ and Hwang KC: Cell adhesion and long-term survival of transplanted mesenchymal stem cells: A prerequisite for cell therapy. Oxid Med Cell Longev 2015: 632902, 2015.

10. Chang W, Song BW, Moon JY, Cha MJ, Ham O, Lee SY, Choi E, Choi E and Hwang KC: Anti-death strategies against oxidative stress in grafted mesenchymal stem cells. Histol Histopathol 28: $1529-1536,2013$

11. Halabian R, Tehrani HA, Jahanian-Najafabadi A and Habibi Roudkenar M: Lipocalin-2-mediated upregulation of various antioxidants and growth factors protects bone marrow-derived mesenchymal stem cells against unfavorable microenvironments. Cell Stress Chaperones 18: 785-800, 2013.

12. Wang Z, Ehnert S, Ihle C, Schyschka L, Pscherer S, Nussler NC, Braun KF, Van Griensven M, Wang G, Burgkart R, et al: Increased oxidative stress response in granulocytes from older patients with a hip fracture may account for slow regeneration. Oxid Med Cell Longev 2014: 819847, 2014.

13. Sies H: Oxidative stress: Oxidants and antioxidants. Exp Physiol 82: 291-295, 1997.

14. Matkowski A,Jamiołkowska-Kozlowska W and Nawrot I: Chinese medicinal herbs as source of antioxidant compounds-where tradition meets the future. Curr Med Chem 20: 984-1004, 2013.

15. Chen XW, Di YM, Zhang J, Zhou ZW, Li CG and Zhou SF: Interaction of herbal compounds with biological targets: A case study with berberine. Scientific World J 2012: 708292, 2012.

16. Mo C, Wang L, Zhang J, Numazawa S, Tang H, Tang X, Han X, Li J, Yang M, Wang Z, et al: The crosstalk between Nrf2 and AMPK signal pathways is important for the anti-inflammatory effect of berberine in LPS-stimulated macrophages and endotoxin-shocked mice. Antioxid Redox Signal 20: 574-588, 2014.

17. Hsu YY, Tseng YT and Lo YC: Berberine, a natural antidiabetes drug, attenuates glucose neurotoxicity and promotes Nrf2-related neurite outgrowth. Toxicol Appl Pharmacol 272: 787-796, 2013.

18. Yi T, Zhuang L, Song G, Zhang B, Li G and Hu T: Akt signaling is associated with the berberine-induced apoptosis of human gastric cancer cells. Nutr Cancer 67: 523-531, 2015.

19. Tan Y, Tang Q, Hu BR and Xiang JZ: Antioxidant properties of berberine on cultured rabbit corpus cavernosum smooth muscle cells injured by hydrogen peroxide. Acta Pharmacol Sin 28 1914-1918, 2007

20. Campisi A, Acquaviva R, Bonfanti R, Raciti G, Amodeo A, Mastrojeni S, Ragusa S and Iauk L: Antioxidant properties of Berberis aetnensis C. Presl (Berberidaceae) roots extract and protective effects on astroglial cell cultures. Scientific World Journal 2014: 315473, 2014
21. Li Z, Geng YN, Jiang JD and Kong WJ: Antioxidant and anti-inflammatory activities of berberine in the treatment of diabetes mellitus. Evid Based Complement Alternat Med 2014: 289264, 2014

22. Hsu YY, Chen CS, Wu SN, Jong YJ and Lo YC: Berberine activates Nrf2 nuclear translocation and protects against oxidative damage via a phosphatidylinositol 3-kinase/Akt-dependent mechanism in NSC34 motor neuron-like cells. Eur J Pharm Sci 46: 415-425, 2012.

23. Zhang W, Su X, Gao Y, Sun B, Yu Y, Wang X and Zhang F: Berberine protects mesenchymal stem cells against hypoxia-induced apoptosis in vitro. Biol Pharm Bull 32: $1335-1342,2009$

24. Li X, Zhang Y and Qi G: Evaluation of isolation methods and culture conditions for rat bone marrow mesenchymal stem cells. Cytotechnology 65: 323-334, 2013.

25. Ishitsuka K, Hideshima T, Hamasaki M, Raje N, Kumar S, Hideshima H, Shiraishi N, Yasui H, Roccaro AM, Richardson $\mathrm{P}$, et al: Honokiol overcomes conventional drug resistance in human multiple myeloma by induction of caspase-dependent and-independent apoptosis. Blood 106: 1794-1800, 2005

26. Wang Z, Wang D, Li Y and Zhang X: Protective effects of Verapamil against $\mathrm{H} 2 \mathrm{O} 2$-induced apoptosis in human lens epithelial cells. Biomol Ther (Seoul) 22: 553-557, 2014.

27. Tetz LM, Kamau PW, Cheng AA, Meeker JD and Loch-Caruso R: Troubleshooting the dichlorofluorescein assay to avoid artifacts in measurement of toxicant-stimulated cellular production of reactive oxidant species. J Pharmacol Toxicol Methods 67: 56-60, 2013.

28. Qi B, Ji Q, Wen Y, Liu L, Guo X, Hou G, Wang G and Zhong J: Lycium barbarum polysaccharides protect human lens epithelial cells against oxidative stress-induced apoptosis and senescence. PloS One 9: e110275, 2014.

29. Sun B, Feng M, Tian X, Lu X, Zhang Y, Ke X, Huang S, Cao J and Ding X: DL-3-n-Butylphthalide protects rat bone marrow stem cells against hydrogen peroxide-induced cell death through antioxidation and activation of PI3K-Akt pathway. Neurosci Lett 516: 247-252, 2012

30. Matsuda S, Nakanishi A, Wada Y and Kitagishi Y: Roles of PI3K/AKT/PTEN pathway as a target for pharmaceutical therapy. Open Med Chem J 7: 23-29, 2013.

31. Panteli M, Pountos I, Jones E and Giannoudis PV: Biological and molecular profile of fracture non-union tissue: Current insights. J Cell Mol Med 19: 685-713, 2015

32. Sotiropoulou PA and Papamichail M: Immune properties of mesenchymal stem cells. Methods Mol Biol 407: 225-243, 2007.

33. Pountos I, Georgouli T, Kontakis G and Giannoudis PV: Efficacy of minimally invasive techniques for enhancement of fracture healing: Evidence today. Int Orthop 34: 3-12, 2010.

34. Liu N, Zhang Y, Fan L, Yuan M, Du H, Cheng R, Liu D and Lin F: Effects of transplantation with bone marrow-derived mesenchymal stem cells modified by Survivin on experimental stroke in rats. J Transl Med 9: 105, 2011.

35. Toma C, Pittenger MF, Cahill KS, Byrne BJ and Kessler PD Human mesenchymal stem cells differentiate to a cardiomyocyte phenotype in the adult murine heart. Circulation 105: 93-98, 2002.

36. Ilavenil S, Kim da H, Jeong YI, Arasu MV, Vijayakumar M, Prabhu PN, Srigopalram S and Choi KC: Trigonelline protects the cardiocyte from hydrogen peroxide induced apoptosis in H9c2 cells. Asian Pac J Trop Med 8: 263-268, 2015.

37. Earnshaw WC, Martins LM and Kaufmann SH: Mammalian caspases: Structure, activation, substrates, and functions during apoptosis. Ann Rev Biochem 68: 383-424, 1999.

38. Chen J, Crawford R, Chen C and Xiao Y: The key regulatory roles of the PI3K/Akt signaling pathway in the functionalities of mesenchymal stem cells and applications in tissue regeneration. Tissue Eng Part B Rev 19: 516-528, 2013.

39. Yang P, Peairs JJ, Tano R and Jaffe GJ: Oxidant-mediated Akt activation in human RPE cells. Invest Ophthalmol Vis Sci 47: 4598-4606, 2006. 